\title{
PROGRAMA DE AÇÕES AFIRMATIVAS NA UFSM: O ENSINO SUPERIOR PÚBLICO SOB O OLHAR DE SEUS GESTORES
}

http://dx.doi.org/10.5902/21762171989

\author{
Cláudia Regina Costa Pacheco \\ Instituto Federal de Educação, Ciência e Tecnologia do \\ Rio Grande do Sul/IFRS - campus Ibirubá
}

\begin{abstract}
Resumo
Este trabalho apresenta os resultados da pesquisa sobre ações afirmativas na Universidade Federal de Santa Maria - UFSM. Questionou-se: em que medida a implantação de um programa de ações afirmativas na UFSM pode contribuir para os processos de democratização no ensino superior? O objetivo deste estudo é compreender o processo de implantação do Programa de Ações Afirmativas e as contribuições que este programa pode trazer para uma democratização do ensino superior. Buscou-se apreender como aconteceu o processo de implantação, acesso e permanência nos cursos da UFSM. A universidade, configurando-se num espaço de construção de identidades, também precisa desempenhar o papel de mediadora no processo de construção de cidadania. A participação conjunta de professores, gestores, alunos e comunidade em geral enriquece o planejamento e possibilita uma melhor atuação frente à diversidade escolar.

Palavras-chave: ações afirmativas, ensino superior, gestão educacional.
\end{abstract}

\section{AFFIRMATIVE ACTION'S PROGRAM AT UFSM: THE PUBLIC HIGHER EDUCATION UNDER THE WATCH OF YOURS MANAGERS}

\begin{abstract}
This work presents a study made at UFSM about Affirmative Action's Program. The basic question in this work is: to what extent may the program affirmative action's implementation at UFSM contribute to a democratic public higher education managing? This research's main objective is to comprehend the Affirmative Action program's implementation and its contributions to a democratic higher education managing. It is needed first to apprehend the process of implementation, access and permanency apprehension at UFSM. The university configuring itself to a place where there is the construction of identities, also needs to develop a role of mediator in the process of citizenship construction, to that the participation of teachers, managers, students and the community is elementary, this combined action enriches the planning and allows better actions facing the schooling diversity.

Key-words: affirmative action, higher education, educational managing.
\end{abstract}




\section{Introdução}

- ste artigo apresenta os estudos realizados sobre as ações afirmativas na Universidade Federal de Santa Maria - UFSM. Nesse sentido, a questão que norteou todo este trabalho foi: em que medida a implantação de um programa de ações afirmativas na UFSM pode contribuir para os processos de democratização no ensino superior? O objetivo primeiro desta investigação está em compreender o processo de implantação do Programa de Ações Afirmativas e as contribuições que este programa pode trazer para uma democratização do ensino superior.

$\mathrm{O}$ presente artigo subdivide-se em três partes. Na primeira, intitulada Políticas públicas e gestão no ensino superior: discutindo compromissos sociais, abordam-se os fenômenos da globalização e da exclusão social pensando a realidade brasileira marcada por estigmas e discriminações. Além disso, apresenta algumas considerações sobre o processo democrático brasileiro e o panorama sul-brasileiro das cotas. Na segunda parte, Ações afirmativas nas IES: o caso da UFSM, trata-se das ações de implantação, acesso e permanência. $\mathrm{Na}$ terceira parte, Programa de ações afirmativas no olhar dos gestores, analisam-se os dados obtidos pelo diálogo com alguns pró-reitores da UFSM.

\section{Políticas públicas e gestão no ensino superior}

O Brasil, em 1996, definiu e regularizou o seu sistema de educação a partir da Lei de Diretrizes e Bases da Educação Nacional. Esta lei, considerada como um dos mais importantes pilares que sustentam a educação institucional brasileira trouxe, como enfoque máximo, a inclusão social.

Passados mais de dez anos de sua aprovação a LDB ainda tem desafios para vencer, entre os quais se pode destacar: a garantia da permanência dos estudantes na educação superior, a desmercantilização da oferta desse nível de ensino, o estabelecimento de mecanismos efetivos de aferição e controle da qualidade (Bittar; Oliveira; Morosini, 2008).

Ristoff (2008) esclarece que a expansão não pode ser confundida com democratização. A expansão se define pelo crescimento expressivo do sistema, com índices que chegam a, aproximadamente, $120 \%$ para as instituições e as matrículas e $180 \%$ para os cursos de graduação presencial. Nesse sentido, a ampliação do acesso nos remete ao fato de que a expansão da educação superior não teve apenas um sentido de ampliação geográfica, mas também de ampliação de oportunidades de acesso para setores da classe média até então excluídos desse nível de ensino.

O Instituto Brasileiro de Geografia e Estatística informa, há algum tempo, que entre os estudantes do ensino médio, há milhões deles tão pobres que, mesmo que a educação superior seja pública e gratuita, terão dificuldades de se manterem no campus (Ristoff, 2008). Percebe-se a necessidade de programas institucionais e de governo que repensem a permanência desses alunos na universidade. Associa-se a esta preocupação os acontecimentos e as ações que ocorrem na UFSM, tendo em vista a adoção de um programa de ações afirmativas, bem como a participação no Programa de Reestruturação e Expansão das Universidades Federais - Reuni'.

Cabe salientar que o Reuni fundamentou-se na idéia de democratizar o acesso e a permanência nas universidades federais. Conjugando verbos como reestruturar, expandir,

1 Decreto n. 6.096, de 24 de abril de 2007.

Regae: Rev. Gest. Aval. Educ. Santa Maria

v. 2

ก. 4

Jul/dez. 2013

p. 7-21 
ampliar, racionalizar e otimizar, o Reuni apresentou como meta global a elevação gradual da taxa de conclusão média dos cursos de graduação presenciais para noventa por cento e da relação de alunos de graduação em cursos presenciais por professor para dezoito, ao final de cinco anos, a contar do início de cada plano.

Neste cenário, ao lado da ampliação do acesso, com o melhor aproveitamento da estrutura física, e do aumento qualificado de recursos humanos, está a preocupação de garantir a melhoria da qualidade da graduação da educação pública, baseada na flexibilização curricular e na mobilidade acadêmica. Se a palavra de ordem da década passada foi expandir, a desta década foi democratizar. $E$ isto significou criar oportunidades para que os milhares de jovens de classe baixa tenham acesso à educação superior (Ristoff, 2008).

Antes de introduzir questões referentes aos processos democráticos cabe compreender os fenômenos da globalização e da exclusão social, tendo em vista que o entendimento destes dois fenômenos possibilita a compreensão do contexto brasileiro. Se pensarmos na realidade brasileira, marcada por estigmas e discriminações, além de possuir uma cultura de dependência, podemos ressaltar a vulnerabilidade da educação exposta à exploração e a legitimação de modelos que não correspondem às expectativas locais.

A discussão sobre os processos de globalização e de exclusão social se sobressai neste contexto, conforme afirma Nascimento (1997), como fenômenos que, para uns, aceleram o fim da modernidade, enquanto para outros aprofundam a sua crise. De acordo com esse autor, não existe um consenso sobre o significado de nenhum dos termos: modernidade, globalização e exclusão.

No que tange à exclusão social, observa-se que seu campo teórico é múltiplo e muitos são os autores que refletem sobre essa temática. Nesse contexto, a dimensão central nos estudos em torno da exclusão é ainda a econômica e, mais precisamente, a do mercado de trabalho. A dimensão política, do mesmo modo, apresenta-se como essencial nos processos de exclusão, pois a ausência de direitos coloca os indivíduos em situação de precariedade e, sobretudo, de dificuldade em mudar sua situação econômica.

Pela Constituição de 1988 se institucionalizou a instauração de um regime democrático no Brasil. A sociedade democrática foi concebida como aquela que não esconderia suas divisões e consequentes incongruências, mas que procuraria trabalhálas, considerando legítimos os conflitos. Esta Constituição trouxe avanços significativos no fortalecimento legislativo das garantias e nos direitos fundamentais. Esse período histórico foi marcado pelo fortalecimento de novos paradigmas nas ciências sociais e humanas. Deflagrado o processo de democratização da sociedade brasileira após o período de vinte e um anos de governo militar, cabe discutir que tipo de democracia foi esse e quais as repercussões desse processo para o contexto da educação atual. A sociedade tem tido muitas influências de decisões externas que fogem ao seu controle. Um exemplo disso se refere à questão da gestão democrática que é assegurada, tanto na Constituição de 1988 ,quanto na LDB e que é guiada por projetos neoliberais globalizados.

Foi a partir da Constituição de 1988 e da LDB que a gestão escolar agregou os princípios democráticos. Denomina-se então gestão escolar democrática. Esta gestão passa a ser o resultado da atuação de todos os componentes da comunidade escolar 
frente às metas estabelecidas pelos projetos político-pedagógicos. A gestão democrática, enquanto gestão participativa, tem como fundamentos principais a participação e a autonomia.

Os conceitos de gestão educacional e gestão escolar estão de tal forma imbricados que em diversos momentos são tidos erroneamente como sinônimos. Sendo assim, cabe ressaltar que a gestão educacional diz respeito ao resultado do processo de articulação nas diferentes instâncias educacionais de governo. Constitui-se, então, no campo das normatizações de leis que gestam a educação. A gestão educacional se ocupa com a esfera macro da educação. A gestão escolar se sobressai no campo da escola.

Após essa contextualização referente aos processos de globalização e exclusão social e a breve discussão sobre a questão da democracia, introduz-se o foco desta pesquisa que buscou entender as ações afirmativas enquanto um dos principais pontos conflitantes do projeto de reforma universitária, como expressão das políticas públicas de educação superior.

Assim, é necessário compreender os três primeiros anteprojetos de reforma universitária. O Ministério da Educação apresentou a primeira versão da reforma universitária em dezembro de 2004, com vistas a restabelecer a centralidade do papel do Estado como mantenedor das instituições de ensino superior e regulador do sistema de educação superior. Buscou, ainda, definir também as condições objetivas para o exercício da autonomia universitária. A segunda versão, apresentada em maio de 2005, demonstrou-se mais enxuta que a redação anterior e buscou compor os diversos interesses em jogo, sem abrir mão de cláusulas essenciais². Em julho de 2005 foi entregue a versão final do anteprojeto de lei da reforma do ensino superior. A absorção de críticas recebidas, especialmente pela primeira versão do projeto, é evidente a partir da segunda versão. Entretanto, alguns pontos essenciais permanecem, apesar de seu caráter polêmico. Os principais são a questão das cotas e a restrição contra a participação do capital internacional no âmbito das instituições de ensino superior. Devese perceber a importância estratégica desses pontos no âmbito do projeto. A partir da exposição de motivos da reforma, o Ministério da Educação fez uma análise dos três anteprojetos, sintetizando-a da seguinte forma: o primeiro define diretrizes e princípios, o segundo afirma e consolida as diretrizes e princípios e o terceiro constitui-se na versão preliminar do anteprojeto de lei e estabelece as normas gerais e a regulação do sistema federal de educação superior.

Todavia, a discussão contextual trouxe consigo conseqüências concretas, embora o projeto final da reforma não tenha ainda sido votado pelo Congresso Nacional. Nesse sentido, os mecanismos de ação afirmativa passaram a ser mais destacados a partir da discussão do tema na reforma universitária. Ainda está no Congresso para ser examinado o projeto de lei n. 73/99, ou Lei de Cotas, que tem como objetivo normatizar a criação de um sistema especial de reserva de vagas para estudantes egressos de escolas públicas, em especial negros e indígenas, nas instituições públicas federais de educação superior.

Pode-se observar que houve uma adesão progressiva de várias universidades estaduais e federais aos sistemas de ingresso diferenciado, como reserva de vagas, de

2 Os projetos de lei aqui citados podem ser encontrados no site oficial do Ministério da Educação: www.mec.gov.br 
forma a instituir programas de ações afirmativas tendo como estratégia as cotas para demandas específicas, especialmente cotas raciais.

Atualmente muitas foram as mudanças no contexto universitário, além desta adesão das universidades às políticas de ações afirmativas, a adoção do novo Exame Nacional do Ensino Médio - Enem - como forma de ingresso, a responsabilização da União pela formação de professores da educação básica, a criação do Programa de Apoio a Planos de Reestruturação e Expansão das Universidades Federais - Reuni - e a interiorização das instituições públicas de ensino superior.

No contexto das universidades federais da região Sul do país, a Universidade Federal do Paraná foi a pioneira na instituição da política de $\operatorname{cotas}^{3}$. No ano de 2007 foi a vez da Universidade Federal do Rio Grande do Sul aprovar a política de ações afirmativas, que previa a reserva de vagas étnico-raciais e sócio-econômicas. Ainda no ano de 2007 a Universidade Federal de Santa Catarina e a Universidade Federal de Santa Maria discutiram a adoção da política de reserva de vagas.

\section{Ações afirmativas nas IES: o caso da UFSM}

A UFSM, após muitos debates e discussões, aprovou o Programa de Ações Afirmativas de Inclusão Racial e Social. Apesar de muita polêmica, a universidade instituiu o programa e desenvolve ações para dar continuidade a sua implantação. Na sequência são apresentadas algumas considerações sobre a implantação, através do acesso, acompanhamento e conseqüente permanência dos estudantes.

Em maio de 2006, pela portaria n. 49.094, o reitor da UFSM constituiu uma comissão com a finalidade de elaborar um projeto de resolução referente à adoção de ações afirmativas de acesso ao ensino superior gratuito. Foi também instituída uma comissão, ligada à Pró-Reitoria de Graduação, para fomentar a discussão no âmbito acadêmico da proposta. Além disso, foi criado o Observatório de Ações Afirmativas para acesso e permanência nas Universidades Públicas da América do Sul - Afirme constituído por professores, estudantes e servidores da UFSM.

No mês de setembro de 2006 foi realizado o Seminário Internacional Ações Afirmativas e Educação Superior na América do Sul. Este seminário destinou-se a analisar a experiência brasileira de ações afirmativas na educação superior e provocar a sua discussão em âmbito regional, como meio de enriquecê-la. Ainda neste mês, o reitor da UFSM assinou a portaria n. 49.772 designando a Comissão Consultiva e de Acompanhamento da Regulamentação e Implantação da Política de Ações Afirmativas. A Comissão foi composta por representantes do Núcleo de Estudos Afro-Brasileiros, da Sedufsm, da Assufsm, do DCE, do Núcleo de Educadores Negros, da Coordenadoria Municipal de Políticas Públicas para a Comunidade Negra e da UFSM.

Em janeiro de 2007 foi entregue ao reitor da UFSM o projeto de resolução sobre o programa de ações afirmativas. Logo após foi encaminhada cópia do referido projeto a todos os setores da UFSM, para a divulgação, conhecimento e manifestação da comunidade universitária. Foi assim que representantes dos nove centros de ensino expuseram as posições da comunidade acadêmica. Nesta mesma oportunidade foram ouvidos quatro especialistas no tema, dentre estes dois professores universitários e dois

\footnotetext{
${ }^{3}$ Resolução n. 37/04, que estabelece e aprova Plano de Metas de Inclusão Racial e Social na Universidade Federal do Paraná. 
juízes federais. Um terceiro espaço de discussão ocorreu em maio de 2007, quando o professor José Jorge Carvalho, autor da resolução que instituiu o Programa de Ação Afirmativa na UNB, foi recebido na UFSM e discutiu com a comunidade acadêmica acerca do tema. Por fim, na reunião do Conselho de Ensino, Pesquisa e Extensão, de 13 de julho de 2007, foi aprovado o projeto de resolução que institui, na UFSM, o Programa de Ações Afirmativas de Inclusão Racial e Social.

No ano de 2008 o vice-reitor da UFSM assinou a portaria n. 53.725 designando a Comissão de Implantação e Acompanhamento do Programa de Ações Afirmativas de Inclusão Racial e Social. O principal objetivo desta comissão consistiu em desenvolver ações que viabilizem a implantação do Programa de Ações Afirmativas, que aperfeiçoem 0 acesso e melhorem a permanência.

A UFSM apresenta duas formas de ingresso aos seus cursos de graduação: o vestibular e o Programa de Ingresso ao Ensino Superior. Além do vestibular para cursos de graduação presenciais, a UFSM também realiza o vestibular EAD que se destina aos candidatos a cursos de graduação na modalidade de educação a distância.

No que tange à implantação do Programa de Ações Afirmativas, a UFSM teve nos anos de 2008 e 2009 suas primeiras experiências. Desde os editais dos processos seletivos a Coperves/Prograd precisou preocupar-se em contemplar os princípios estabelecidos na resolução n. 11/2007. No que diz respeito ao acesso, a referida resolução prevê, no período de dez anos, um percentual de 10 a $15 \%$ das vagas nos processos seletivos para estudantes afro-brasileiros - pretos e pardos conforme classificação do IBGE -, 20\% das vagas para estudantes oriundos de escolas públicas, $5 \%$ para estudantes com necessidades especiais. Todos esses percentuais são previstos em cada um dos cursos de graduação. Além disso, foram previstas, anualmente, vagas suplementares àquelas ofertadas no processo seletivo em cursos de graduação para serem disputadas exclusivamente por alunos indígenas residentes no território nacional, para atendimento das demandas de capacitação de suas respectivas sociedades, apontadas por intermédio da Fundação Nacional do Índio. Dessa forma, a resolução presumiu que o número inicial de vagas seria de cinco para o ano de 2008, passando para oito nos anos de 2009 e 2010, aumentando para dez vagas nos anos subseqüentes.

O edital do vestibular de 2008 estabeleceu o Sistema Cidadão Presente, que foi a maneira de categorizar os diferentes critérios para os vestibulandos. Desse modo, o Sistema Cidadão Presente seguiu a seguinte estrutura: Sistema Cidadão Presente A: para candidatos afro-brasileiros ( $10 \%$ das vagas em cada curso de graduação); Sistema Cidadão Presente B: para candidatos com necessidades especiais $(5 \%$ das vagas em cada curso de graduação); Sistema Cidadão Presente C: para candidatos oriundos de escolas públicas. (20\% das vagas em cada curso de graduação); No vestibular 2008 o candidato pode ter estudado até 1 ano em escola particular; Sistema Cidadão Presente D: para candidatos indígenas residentes em território nacional (total de até 05 vagas, distribuídas nos cursos de graduação em que houver procura); Sistema Cidadão Presente E: para os candidatos que não se enquadrarem nas características anteriores. (Manual do Candidato - Vestibular/2008, p. 10)

Os vestibulares de 2009, bem como o vestibular EAD, também adotaram o Sistema Cidadão Presente, porém com algumas adaptações referentes à resolução 11/2007. Percebemos, no ano de 2009, o aumento da porcentagem de vagas para os candidatos 
afro-brasileiros de $10 \%$ para $11 \%$, conforme estabelecido na resolução 11/2007. Outro elemento que merece destaque é o fato de que neste ano os candidatos do Sistema Cidadão Presente $C$ passam a ter como critério a realização de todo o ensino básico em escolas públicas e não mais é dada a tolerância de um ano em escola particular. $O$ Sistema Cidadão Presente $D$ também sofre algumas alterações no sentido de aumentar o seu número de vagas, passando de 5 para 8 vagas suplementares.

A Comissão de Ações Afirmativas, com vistas ao acompanhamento do Programa de Ações Afirmativas, realizou audiências para a comprovação da autodeclaração dos alunos afro-brasileiros negros. Quanto aos alunos oriundos de escolas públicas foi realizada a conferência da documentação junto ao Departamento de Registro e Controle Acadêmico. Já com os alunos com necessidades especiais foi feita a conferência dos exames médicos comprobatórios da deficiência. Tais medidas foram tomadas não no sentido de discriminar, mas apenas de ter o acompanhamento para evitar burlas ao sistema de cotas.

No que tange a permanência, a resolução n. 11/2007 prevê que:

Art 10. A UFSM deverá implementar um programa permanente de acompanhamento e de apoio sociopedagógico dos estudantes cotistas, segundo sua opção quanto ao disposto nos art. $2^{\circ}$, $3^{\circ}$, e e 4으, desta resolução, coordenado por comissão constituída especificamente para esse fim. Art. 11. A UFSM deverá implementar um programa permanente de acompanhamento dos estudantes indígenas, coordenado por comissão constituída especificadamente para esse fim.

Tendo em vista que o Programa é recente na UFSM, não se tem ainda resultados concretos, mas penso que o primeiro passo foi dado. Se defendemos tanto uma sociedade igualitária no respeito às diferenças, precisamos agir em busca desses ideais. A universidade é apenas um dos muitos lugares que necessitam de alternativas para a promoção de relação e respeito entre os grupos sócio-culturais. Como formadora de professores, a universidade precisa de políticas que contemplem a diversidade cultural. Sua inter-relação com a escola é fundamental.

\section{Programa de ações afirmativas no olhar dos gestores}

Para compreender como se efetiva o Programa de Ações Afirmativas na UFSM, nada melhor do que ouvir os seus gestores. Diante disso, foram colaboradores desta pesquisa oito pró-reitores, entre titulares e adjuntos, dentre eles: os pró-reitores de graduação, de pós-graduação e pesquisa, de assuntos estudantis e de extensão. Para preservar os colaboradores desta pesquisa estes foram citados pelas siglas: PR1, PR2, PR3, PR4, PR5, PR6, PR7 e PR8.

Para a coleta de dados fez-se uso de um questionário com questões abertas, que possibilitaram aos colaboradores expressarem-se com liberdade. O questionário foi constituído por quatro perguntas: 1) O que você entende por ações afirmativas? 2) Qual a sua opinião sobre as ações de implantação do Programa de Ações Afirmativas nas universidades públicas brasileiras, sobretudo, no contexto das IES do Rio Grande do Sul? 3) Qual a sua opinião sobre as ações de implantação do Programa de Ações Afirmativas na UFSM? 4) Para você, a implantação de uma política de ações afirmativas pode contribuir de alguma maneira para os processos de democratização no ensino superior? 
A partir das respostas dadas pelos colaboradores pode-se compreender como os gestores entendem essa política implementada pela UFSM, fato este que pode influenciar de modo direto ou indireto na atuação destes pró-reitores, tendo em vista os novos desafios a serem enfrentados pela universidade ao aderir a esta política.

O termo ação afirmativa surgiu nos EUA, nos anos de 1960. Como proposta, o termo carrega uma infinidade de sentidos e reflete também a experiência histórica brasileira da desigualdade social. Ação afirmativa é planejar e atuar no sentido de promover a representação de determinados segmentos de pessoas, sobretudo, aquelas pertencentes a grupos que têm sido subordinados ou excluídos (Garcia, 2007).

O conceito de ações afirmativas é descrito de diferentes formas pelos pró-reitores, porém suas respostas se complementam. Enfatizaram em suas respostas, o caráter político dos programas de ações afirmativas nas universidades, sobretudo no caso da UFSM. Nessa perspectiva, ação afirmativa é considerada pelo PR4 como uma "iniciativa política para dar condições de igualdade aos menos providos". O PR1 completa essa ideia ao destacar que "ações afirmativas são políticas de estado e ações de governo que podem envolver também ações da sociedade civil, que dizem respeito, no caso brasileiro, a criação de condições materiais de igualdade. Especialmente as previstas no artigo $5^{\circ} \mathrm{da}$ Constituição brasileira que prometem que todos os brasileiros são iguais".

Percebo que o conceito de ações afirmativas se delineia com a criação de condições de igualdade de oportunidades. A resposta do PR2 complementa essa ideia ao afirmar que ações afirmativas

são aquelas ações que abrem novos espaços e caminhos para grupos da população em condição inferiorizada (econômica e socialmente) ao longo da história. Estes espaços e caminhos são pensados no sentido de promover igualdade de oportunidades para que seja desenvolvido ao máximo o potencial individual em prol do bem comum. Trata-se numa aposta muito séria em um vir a ser a partir de um ser real hoje que reconhece o seu elevado potencial de desenvolvimento e a satisfação em realizar e vencer este desafio, com base no profundo reconhecimento da dignidade de cada ser humano e sua história de vivências que o tornam portador de experiências, muitas vezes únicas e que podem inspirar soluções para os problemas seus e de outros indivíduos e/ou comunidades. (PR2)

O que há de semelhante nessa ideia de ações afirmativas é a perspectiva de uma restituição de uma igualdade que historicamente foi rompida, ou nunca existiu. Concordo com Garcia (2007) quando afirma que numa sociedade multifacetada como a brasileira, é preciso lembrar que a história da educação dos diferentes grupos (étnicos, sociais, etc.) indica-nos processos discriminatórios no sistema educacional oficial, que não são facilmente perceptíveis. Deste modo, estar atento as populações menos favorecidas é questão de cidadania e de abrir campos para a consolidação efetiva de políticas públicas que atuem no sentido de minimizar a pobreza e a exclusão a que foram submetidos ao longo dos séculos.

Assim, as ações afirmativas podem ser também concebidas como um

conjunto de iniciativas tomadas nas esferas públicas, legislativa e executiva, decorrentes das mobilizações dos estratos populares que sofrem restrições de caráter físico, moral e cultural. Através da formulação 
de políticas públicas são atendidas expectativas dos diferentes segmentos da Sociedade, que possuem caráter inclusivo nos meios privados e públicos de convivência. (PR7)

Sendo medidas temporárias determinadas pelo Estado, de modo espontâneo ou compulsório, as ações afirmativas têm com o propósito de compensar perdas econômicas, sociais, políticas, eliminar desigualdades e garantindo oportunidades, que devido à discriminação e à marginalização eram negligenciadas para determinados grupos.

Cabe ressaltar outro fator que se destaca nas respostas dos colaboradores que é a questão do reconhecimento da dignidade humana. Tal questão também é sublinhada pelo PR3 quando ele conceitua as ações afirmativas como "ações que visam prioritariamente dignificar os seres humanos, dando-Ihes acolhimento e proporcionando oportunidades de autorealização, no caso da UFSM. Transparece na possibilidade de não só participar, mas principalmente em poder concluir seus cursos" (PR3).

Oportunidade aparece como palavra-chave nessa discussão. Este vocábulo tem grande reincidência nas respostas dos pró-reitores. Direta ou indiretamente, eles mencionam que as ações afirmativas referem-se à criação de novas oportunidades, sobretudo no acesso ao ensino superior público. Desse modo,

ações afirmativas se constituem em um conjunto de ações que pretendem modificar o perfil do aluno das IFES públicas, facilitando o ingresso e manutenção de oriundos de classes sociais ou grupos étnicos que não conseguem ingressar no ensino superior pelos métodos atuais. (PR6)

A segunda questão proposta aos pró-reitores foi qual a sua opinião sobre as ações de implantação da política de ações afirmativas nas universidades públicas brasileiras, sobretudo, no contexto das IES do Rio Grande do Sul? Diante deste questionamento ressaltaram-se inúmeros aspectos que nos permitem uma melhor compreensão de suas percepções acerca da implantação da política em âmbito nacional e estadual.

Dessa forma, um primeiro elemento que merece ênfase diz respeito ao papel da universidade junto à sociedade civil. Conforme o relato do PR1, podemos observar a sua concepção de universidade como instituição que corresponde aos anseios da sociedade brasileira. Neste sentido, ele afirma que

as universidades federais como parte da estrutura do estado, algumas são fundações outras são autarquias, elas devem corresponder aos desejos da sociedade brasileira. Em que se consideram expressas na Constituição Federal de 1988 e que, portanto, obrigam a Universidade a agir no sentido de contribuir com outros entes estatais ou civis para a realização das promessas constitucionais que os brasileiros se fizeram a si mesmos, desculpem a redundância, por ocasião da promulgação da Carta de 1988, a chamada Constituição Cidadã. A repercussão da ação das Universidades, promovendo Ações Afirmativas, que escape o âmbito da sua possibilidade de atuação, portanto legitima no ponto de vista do papel que lhe cabe dentro da estrutura do próprio Estado. Se estas ações, especialmente, aquelas relacionadas as reservas de vagas para diferentes categorias, historicamente, alijadas do acesso a Universidade geram discussões isso me parece que deve ser encarado positivamente uma vez que é próprio da produção do conhecimento, da qualidade do conhecimento que se espera que seja produzido em uma Universidade há 
produção de conflito. O conflito é a base da produção do humano, é a base da produção de um conhecimento que seja socialmente produtivo, no sentido de solucionar os problemas com os quais nós nos debatemos cotidianamente, mesmo que não queiramos. Eu tenho a impressão que a questão fundamental, nesta discussão das Ações Afirmativas, com reserva de vagas, cotas, como normalmente se diz, que no caso da minha universidade, a Universidade Federal de Santa Maria, são cotas para estudantes oriundos de escolas públicas, que tenham feito todo o ensino em escolas públicas, para negros afro-brasileiros, para pessoas com necessidades educativas especiais, deficientes como prevê a própria legislação e, para indígenas, ela, sem dúvida nenhuma, cria uma possibilidade imensa da Universidade representar melhor a própria sociedade e em representando assim, portanto, os próprios interesses da sociedade como um todo. (PR1)

A implantação de um Programa de Ações Afirmativas tem gerado inúmeras discussões. Diante da polêmica a universidade pública tenta a sua maneira implantar de modo circunspecto um programa que dê conta das necessidades e aspirações da sociedade. O PR7 afirma que

mesmo que muitas vezes de forma polêmica e atribulada, as universidades públicas brasileiras se anteciparam em atender anseios da Sociedade, ocupando espaços que caberiam aos legisladores, e aplicaram medidas que representam avanços em relação a uma situação marco zero. Deixando de lado o discurso interminável, enfadonho e carcomido de representantes de elites econômicas e políticas do país, pautado na desinformação, na ignorância sobre a história e a cultura do povo brasileiro e na ausência de espírito verdadeiramente social-democrático, os gestores e as comunidades universitárias de alguns estados do Brasil, inclusive do Rio Grande do Sul, priorizaram o debate, ainda que eivado de discórdias, e passaram a aplicar as primeiras medidas pró-ativas. No Rio Grande do Sul, superando apenas o viés dos debates acadêmicos, em termos de pesquisa e produção de conhecimento através dos programas de pósgraduação, o destaque maior cabe à UFSM que criou um Programa de efetiva resolutividade, o qual tem demonstrado na prática bons resultados. Certamente muito ainda teremos que avançar, no sentido de refletir sobre problemas e resultados, mas também de propiciar a expansão de atendimento das demandas. Pessoalmente, entendo que a melhor política - mais abrangente e justa socialmente - é a qualificação da escola pública estatal nos seus ensinos fundamental e médio, com a retomada de sua excelente qualidade que vigorou até o início da década de 1980. Nessa escola é possível reunir todos os estratos sociais demandantes de ações afirmativas, os quais pela qualificação alcançada poderiam obter capacitação para escolher o ensino técnico, o ensino universitário, a busca de opções no mercado de trabalho, etc. Assim, não seria necessário apontar esse ou aquele segmento, que infelizmente acabam por serem visto como privilegiados, já que a cultura popular e das elites não consegue ver o horizonte mais amplo das deficiências e limitações das pessoas e dos grupos especiais, os quais tem particularidades que demonstram suas reais diferenças. (PR7)

Observo nas palavras deste pró-reitor que a implantação de uma política de ações afirmativas não pode ser vista de forma isolada. São muitos os setores que precisam se movimentar para dar conta das injustiças sociais. A universidade é apenas um destes setores. A escola básica é uma das protagonistas nesse processo. Pois de nada adianta 
falarmos em ações afirmativas no ensino superior se não tivermos uma escola pública de qualidade para que os candidatos a uma vaga na universidade tenham um mínimo de preparação para chegarem ao nível superior de ensino.

Ao questionar os pró-reitores sobre qual a sua opinião sobre as ações de implantação do Programa de Ações Afirmativas na UFSM busquei trabalhar as respostas de modo a perceber como está sendo vista esta implantação por aqueles que administram a universidade.

O PR1, até pela sua atuação direta na implantação deste programa junto a UFSM, nos apresenta uma rica explanação sobre o que está representando para a UFSM a implantação desta política. Ao analisarmos o histórico da UFSM não é tanta novidade, tendo em vista que a universidade antes mesmo de se pensar na possibilidade de ações afirmativas já vinha instituindo programas de assistência estudantil, programas especiais de ingresso a UFSM, entre outras ações. Disponibilizo, na sequência, a resposta do PR1 na íntegra, sendo ela bastante esclarecedora para contextualizarmos estas ações na UFSM. Dessa forma, o professor diz que

as ações afirmativas na UFSM elas dizem respeito: primeiro, a uma ampla assistência estudantil. A Universidade Federal de Santa Maria há 15 anos através de um programa alternativo de ingresso aos seus cursos de graduação, o PEIES, que é um programa seriado, conseguiu promover uma extraordinária e silenciosa revolução. Mais da metade dos estudantes da UFSM são oriundos de escolas públicas. Esses estudantes oriundos de escolas públicas permitiram 0 acesso a universidade de um grupo considerável de estudantes carentes, que mesmo em uma instituição pública, gratuita e de qualidade como é a UFSM, precisam de assistência estudantil, ou seja, de moradia subsidiada, de alimentação subsidiada, de transporte subsidiado, bolsas de diferenças nuanças para dar conta das suas necessidades de permanência. A UFSM gasta hoje mais de $30 \%$ do seu orçamento na manutenção de uma estrutura de assistência estudantil considerável, que é a maior do país. $\mathrm{E}$, que tem servido de modelo para outras instituições que não tem essa política. Isso decorre mesmo de uma ação afirmativa que é criar alternativas de ingresso que sejam mais universais e criar condições de permanência associadas, então, a qualidade da assistência estudantil ou ao volume da sua aplicação. Então, as ações afirmativas na UFSM não são uma questão nova. Creio que não se pode deixar de lado também a idéia de que o Programa de Acessibilidade da UFSM é uma ação afirmativa. E, finalmente, no conjunto do Programa de Ações Afirmativas há também a reserva de vagas que busca criar as condições materiais de igualdade de acesso a universidade. O nosso Programa de Ações Afirmativas na UFSM tem três bases, ou seja, ele se suporta sobre um tripé, que é de condições materiais de igualdade no acesso; condições de dignidade na permanência e, condições de responsabilidade cidadã na conclusão dos cursos de graduação. Porque mais do que criar igualdade para o acesso, dignidade para a permanência, e isso implica uma série de ações que criem condições adequadas de acompanhamento dos nossos cursos de graduação, inclusive a assistência estudantil. É preciso também completar esse tripé com a responsabilidade dos formadores e de todos os envolvidos com a formação dos nossos estudantes, com a formação de um cidadão que mais do que reprodutor de informações ele seja capaz de problematizar a realidade, depois do curso de graduação, atuar profissionalmente em sua área profissional com uma responsabilidade muito além das fronteiras de sua atuação profissional, como cidadão. $E$, contribuir assim para a sociedade que enfim financiou a 
sua formação. Então essa é a terceira perna desse tripé do Programa de Ações Afirmativas da UFSM que não pode ser desconsiderado. E exige e tem previsto uma série de medidas no sentido de melhorar a qualidade da nossa educação superior da UFSM. (PR1)

A questão de número quatro perguntava: para você a implantação de uma política de ações afirmativas pode contribuir de alguma maneira para os processos de Gestão Democrática no ensino superior? Isso auxilia-nos a entender não só a implantação do programa, como também quais as possíveis relações que esta política pode apresentar junto aos processos de gestão democrática no nível superior de ensino.

Nesta perspectiva, o PR1 destaca que

nós já experimentamos isso na UFSM porque a presença do diferente ela não passa incólume, ela gera movimento, ela gera conflito, ela gera desconforto. E desconfortos que podem ser compreendidos nos seus aspectos objetivos. Nós acabamos nos dando conta que a presença de cadeirantes, de cegos, de surdos, por exemplo, das limitações das nossas instalações, das limitações e da precariedades do nosso sistema de comunicação ou informação e da limitação ao acesso as nossas estruturas físicas. Mas, isso só acontece quando esses sujeitos estão presentes nesses espaços, onde nós realizamos a universidade. Isso são as ações objetivas. E os subjetivos são os que se relacionam com a derrubada de barreiras na cabeça das pessoas. Os preconceitos velados, os temores velados que estão na base desses preconceitos que só são derrubados pela falta da presença do outro, do diferente. E isso contribui, sem dúvida nenhuma, para a mudança de uma cultura institucional que é rica em possibilidades de produção do humano e de um conhecimento que enfim com o objetivo da universidade que seja mais humanizado. Que seja menos tecnificado como a que a modernidade impôs, mesmo a universidade, que seja mais humano. Que se preocupe com a amplitude das possibilidades humanas, das necessidades humanas. E essa presença do diferente na universidade, do indígena, do negro, mas também de diferentes comportamentos, de diferentes culturas é fundamental para que a universidade se torne de verdade esse espaço rico de possibilidades. (PR1)

Na mesma linha de raciocínio o PR2 afirma:

Com certeza, uma vez que a própria necessidade de avaliar a implantação e andamento das ações gera mudanças na gestão, tornando-a mais democrática na medida em que diversos fóruns são trabalhados e ouvidos, proporcionando o acesso de um maior número de pessoas pensando e opinando sobre as PAAs (Política de Ações Afirmativas) e ampliando o leque de pensadores da questão. Outro aspecto a considerar é o caráter temporário limitado em que as ações estarão em vigor, o que pode redirecionar o foco na medida em que certas limitações são vencidas e novas precariedades surgem ou são percebidas. (PR2)

O PR8 entende que

a uma gestão democrática universitária efetiva se consubstancia através de inúmeras situações. São questões operacionais de ordem técnicaadministrativa, financeira, pedagógica e das relações comunitárias que sempre priorizam contextos de mobilização do interesses coletivos, para depois atender necessidades de pequenos grupos ou as individuais. $O$ perfil dos seus dirigentes universitários deve demonstrar capacidade para 
ver e entender tal universo, isto é, visualizar os diferentes interesses em jogo e as necessidades globais da comunidade que lideram. Daí, políticas pensadas e gestadas que atendam primeiramente as demandas de maior número possível de pessoas. Isso vale prioritariamente para as iniciativas acadêmicas fins, como o ensino, a pesquisa, a pós-graduação e a extensão, e secundariamente para o viés administrativo, mesmo reconhecendo a importância desse setor. Contudo, as esferas burocráticas nunca devem estar sobrepostas aos interesses de formação do ensino e das relações da Instituição com a Sociedade. As ações afirmativas constituem apenas mais um elemento da capacidade gerencial dos administradores que tem perfil democrático. Se outras demandas de interesse social ou das comunidades internas das Universidades forem pautadas, caberá a esses administradores o poder de decisão para encaminhá-las e defendê-las. No caso da UFSM as ações afirmativas não foram unanimidade e ainda constituem tema de debates. Mas é inegável que os administradores souberam avaliar o momento e os riscos para implantarem o processo na Instituição. Gerir é tomar decisões. Podem não ser elas as melhores ou as mais justas, mas também podem ser elas repensadas e reavaliadas, como está previsto no atual Programa. Assim, as ações afirmativas contribuem, juntamente com inúmeras outras ações no âmbito da UFSM, para qualificar as práticas e a convivência democrática na Universidade. (PR8)

Podemos constatar que, embora os pró-reitores tenham dado diferentes sentidos ao que foi questionado, suas concepções assemelham-se em vários momentos, sobretudo quanto ao conceito de ações afirmativas. A divergência entre suas respostas aparece quando questionados sobre as relações entre ações afirmativas e gestão democrática.

Assim, considero que as ações afirmativas podem de modo indireto contribuírem para os processos de gestão democrática, tendo em vista a sua possibilidade de gerar movimento, conflito e até mesmo desconforto. Esse movimento causado pela implantação destas ações mesmo que temporário provoca um repensar das ações e funções da universidade. O conflito suscita um refletir sobre os limites e possibilidades desta instituição educativa, bem como as suas precariedades frente aos novos tempos e novas aspirações da sociedade brasileira. O desconforto estimula um conjeturar sobre a presença do outro, do diferente, promovendo um questionar de preconceitos velados, a derrubada de barreiras físicas e psicológicas.

Pensar a gestão democrática no ensino superior é pensar em ações efetivas frente aos desafios diários enfrentados pelas universidades. Os gestores convivem com esse clima cotidianamente e precisam estar preparados para os novos acontecimentos no âmbito universitário e fora deste. A adoção de uma política de ações afirmativas promove um repensar na estrutura da universidade e oportuniza que novos grupos insiram-se nesse espaço historicamente elitizado, onde se tinha lugar apenas para poucos. A diversidade vem para enriquecer e não para desmerecer o ensino superior.

\section{Considerações finais}

O campo de estudos das ações afirmativas tem sido, nos últimos anos, espaço de grandes discussões o que tem provocado um aumento considerável no número de pesquisas realizadas. As discussões vêm para enriquecer, complementar e aumentar nossos conhecimentos no âmbito da educação superior. Tenho a convicção de que as políticas de ações afirmativas são um dos grandes desafios a serem enfrentados pelas 
instituições de ensino superior público brasileiro. Neste trabalho, discutiu-se a gestão democrática por parte da instituição repensar suas ações para que mais grupos tenham acesso a um ensino público, gratuito e de qualidade.

A luta pela inclusão social perpassa a luta pela valorização dos sujeitos, pela aceitação do outro como legítimo outro. Nem a cor, nem a raça, nem a necessidade, nem a condição financeira podem interferir no aprendizado, que é um direito de todos independente de qualquer fator. Valorizar a criatividade, ajudar a conviver com o medo, com o diferente possibilita um enriquecimento e um aperfeiçoamento de todos enquanto humanidade.

Assim, reduzir desigualdades sociais e regionais se traduz na equalização das oportunidades de acesso à educação de qualidade. A universidade configurando-se num espaço de construção de identidades, também precisa desempenhar o papel de mediadora no processo de construção de cidadania.

\section{Referências}

BITTAR, Mariluce; OLIVEIRA, João Ferreira de; MOROSINI, Marília (org.). Educação superior no Brasil - 10 anos pós-LDB. Brasília: Inep, 2008.

EXPOSIÇÃO DE MOTIVOS DO ANTEPROJETO DA LEI DO ENSINO SUPERIOR, Brasília, 2005. Disponível em: <http://portal.mec.gov.br>. Acesso em: 10 jul., 2007.

GARCIA, Renísia Cristina. Identidade fragmentada: um estudo sobre a história do negro na educação brasileira: 1993-2005. Brasília: Inep, 2007.

\section{LEI DE DIRETRIZES E BASES DA EDUCAÇÃO NACIONAL - Lei 9394/96.}

MANUAL DO CANDIDATO - VESTIBULAR/ 2008 - UFSM. Disponível em: $<$ http://www.scribd.com/doc/973204/manual-do-candidato-UFSM-2008>. Acesso em: 5 jul., 2009.

MANUAL DO CANDIDATO - VESTIBULAR/ 2009 - UFSM. Disponível em: $<$ http://coperves.proj.ufsm.br/ManualVestibular2009.pdf >. Acesso em: 14 out., 2009.

MINISTÉRIO DA EDUCAÇÃO. Anteprojetos da Reforma Universitária. Disponível em: $<$ www.mec.gov.br>. Acesso em: 13 jul., 2009.

NASCIMENTO, Elimar Pinheiro do. Globalização e exclusão social: fenômenos de uma nova crise da Modernidade? In: DOWBOR, Ladislau. Desafios da globalização. Petrópolis: Vozes, 1997, p. 40-52.

RISTOFF, Dilvo. Educação superior no Brasil - 10 anos pós-LDB: da expansão à democratização. In: BITTAR, Mariluce; OLIVEIRA, João Ferreira de; MOROSINI, Marília (org.). Educação superior no Brasil - 10 anos pós-LDB. Brasília: Inep, 2008, p. 39-50.

SANTOS, Boaventura de Sousa. VI Congresso Brasileiro de Sociologia. Instituto de Filosofia e Ciências Sociais da Universidade Federal do Rio de Janeiro, 1995. 
Cláudia Regina Costa Pacheco é professora no Instituto Federal de Educação, Ciência e Tecnologia do Rio Grande do Sul/IFRS - campus Ibirubá/RS, com graduação em Pedagogia, mestrado e doutorado em Educação.

Endereço: Rua ABS, 42 - 97070-010 - Santa Maria - RS - Brasil.

E-mail: claudiareginapacheco@gmail.com.

Recebido em 15 de fevereiro de 2013.

Aceito em 20 de agosto de 2013. 